\title{
Lower Extremity Joint Moments during Squat and Stoop Lifting
}

\author{
Seonhong Hwang ${ }^{1}$ Youngeun $\mathrm{Kim}^{2}$ and Youngho Kim ${ }^{1,3}$ \\ ${ }_{1}^{1}$ Department of Biomedical Engineering, Yonsei University, South Korea \\ ${ }^{2}$ Department of Mechanical Engineering, Dankook University, South Korea \\ ${ }^{3}$ Institute of Medical Engineering of Yonsei University, South Korea
}

\section{Introduction}

Low back pain(LBP) is a prevalent problem which causes human suffering and cost for workers and their employers. $60 \sim 80 \%$ of the adult population have experiences of LBP at least once in their lifetimes(Campbell et al., 2005; Stuart McGill, 2002; Koopman et al., 2004). Despite improved working conditions, including progress due to automation, many objects in the industry are still handled manually. Among basic manual material handling (MMH) activities, lifting has most frequently been associated with LBP(Hsiang et al., 1997). Recently, there have been many researches about lifting such as three-dimensional motion analyses, musculoskeletal simulations and medical imaging studies. The most commonly advised lifting technique is the squat technique, in which the knees are flexed(Garg and Moore, 1992). It can easily be understood that compliance with this advice is often low, given the high energetic cost of this technique(Garg and Herrin, 1979; Welbergen et al., 1991; Duplessis et al., 1998). Van Dieen et al. (1997) conducted a comprehensive review on 27 biomechanical studies, comparing stoop and squat techniques, and concluded that no justification existed for advocating squat technique. Jager and Luttman(1989) used a threedimensional dynamic model to estimate lumbar compression and found that compression was barely influenced by lumbar curvature. By observations of physiologic, psychologic, biomechanical and clinical evidence on three lifting techniques; squat, semi-squat, and stoop, Leon Straker(2003) reported that all those lifting techniques had both advantages and disadvantages depending on circumstances. These recent studies have shown that many variables exist depending on different lifting methods.

In this study, lumbar, hip, knee, and ankle joint motions and lumbar spine curvatures during squat and stoop lifting of three different weights were analyzed using the 3-D motion analysis to find out the function of lower limb motions contributing to the lumbar joint.

\section{Methods}

Twenty-six young male volunteers who had no problems in both lifting and walking were selected as the subjects in this study (Table 1).Two forceplates(Kistler Instrumente AG, 
Switzerland) and a surface EMG system(MA 300, Motion Lab Systems Inc., USA) were synchronized with the 3D motion analysis system(VICON Motion System Ltd., UK). A total of 31 reflective markers were attached on the anatomical locations according to the VICON Plug-in-Gait marker placement protocol. Besides that, additional four markers(V1 V4) were mounted on the back along the spinous processes to define the spinal curvature. The boxes $(34 \times 34 \times 27.5 \mathrm{~cm})$ weighed 5,10 and $15 \mathrm{~kg}$, and had the same sized handles. Subjects were asked to lift those boxes using two different techniques (squat and stoop) in their comfortable speed. Joint moments and joint powers in the lower extremities were calculated using the inverse dynamics and the support moment was also determined as the summation of all lower extremity joint moments[15]. Paired t-test was used to determine the statistical difference of the maximum lumbar joint moments between the squat and stoop liftings. The Kruskal-Wallis test was used to compare the joint angles and moments with respect to the increase of weights when the lumbar lordosis appears.

\begin{tabular}{|c|c|c|c|c|}
\hline & \multicolumn{3}{|c|}{ Mean \pm S.D } & range \\
\hline Age (year) & 23.5 & \pm & 0.76 & $22 \sim 24$ \\
\hline Weight $(\mathrm{kg})$ & 66.5 & \pm & 6.37 & $55.6 \sim 74.5$ \\
\hline Height $(\mathrm{cm})$ & 172.1 & \pm & 6.03 & $163.4 \sim 183.5$ \\
\hline
\end{tabular}

Table 1. Subject information $(\mathrm{N}=26)$

\section{Results}

\subsection{Joint angles}

The subjects lifted the objects as their own comfortable speed and the mean speeds were $0.59 \mathrm{~m} / \mathrm{s}( \pm 0.14)$ in squat lifting and $0.60 \mathrm{~m} / \mathrm{s}( \pm 0.10)$ in stoop lifting. Figure 1 represents the lower extremity joint angles on the sagittal plane during lifting. Though different weights were lifted, significant differences were not found in the range of motions(ROMs). However, between two techniques, ROMs for the same joints showed significant difference. The knee joint ROM showed the largest difference between two techniques(Fig. 1).

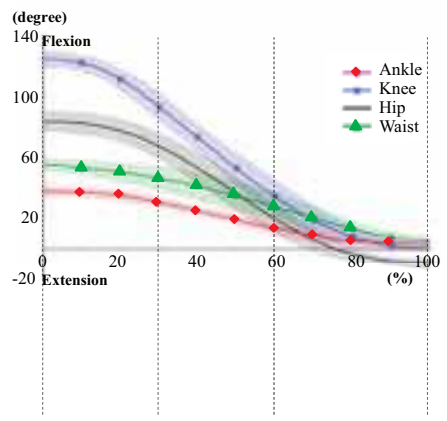

(a) : squat lifting

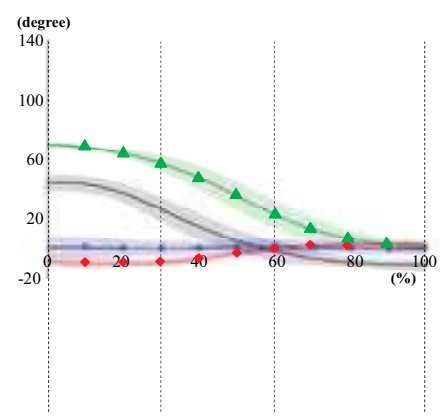

(b) : stoop lifting

Fig. 1. Joint angles of lower extremities during lifting 


\subsection{Joint moments}

Joint moments for the different object weights during squat and stoop lifting were plotted in Fig. 2. The ankle joint moment was larger in the squat lifting than in the stoop lifting. Only the knee flexion moment existed during the whole process of the stoop lifting. However, in the squat lifting, the knee joint moment changed from extension to the flexion moment, and this turn-over occurred earlier as the object weight increased. The hip extension moment increased to its maximum value as soon as lifting started, and then it decreased to nearly zero. For all weights, the maximum hip extension moment in the stoop lifting was always larger than that in squat. The differences of the maximum lumbar extension moments between the squat and stoop were negligible at 5 and $10 \mathrm{~kg}$. Rather, it was larger in squat than in stoop when $15 \mathrm{~kg}$ was lifted $(\mathrm{p}<0.05)$.

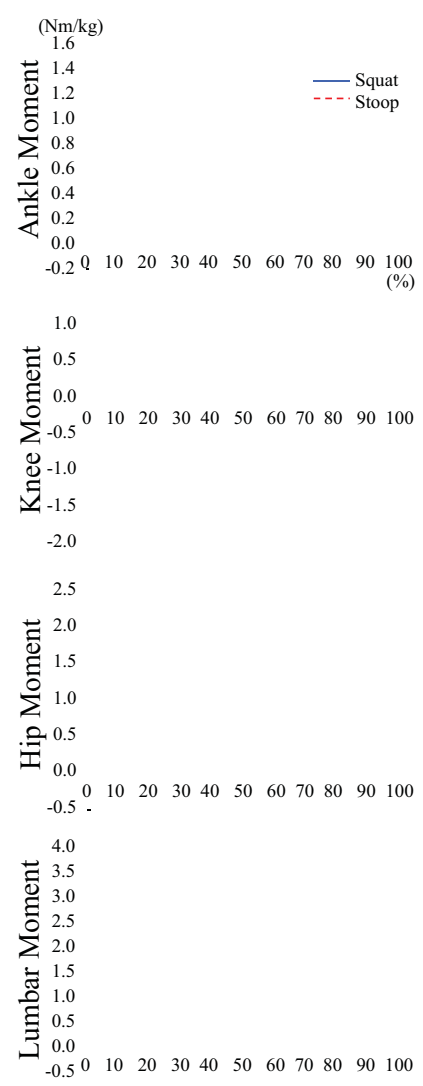

(a): $5 \mathrm{~kg}$

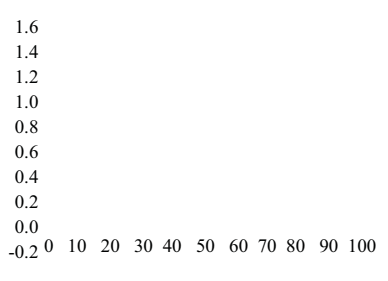

1.0

0.5

$-0.50$

$\begin{array}{llllllllllll}0 & 10 & 20 & 30 & 40 & 50 & 60 & 70 & 80 & 90 & 100\end{array}$

$-1.0$

$-1.5$

$-2.0$

2.5

2.0

1.5

1.0

0.5

0.0

$\begin{array}{rlllllllllll}0.5 & 0 & 10 & 20 & 30 & 40 & 50 & 60 & 70 & 80 & 90 & 100\end{array}$

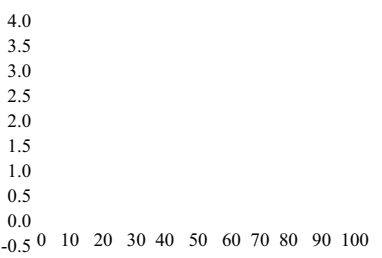

(b): $10 \mathrm{~kg}$

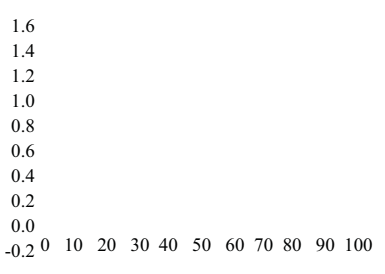

1.0

0.5

$\begin{array}{lllllllllll}0.0 & & & & & & & & & & \\ -0.5 & 10 & 20 & 30 & 40 & 50 & 60 & 70 & 80 & 90 & 100\end{array}$

$-1.0$

$-1.5$

-2.0 .

2.5

2.0

1.5

1.0

0.5

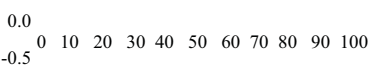

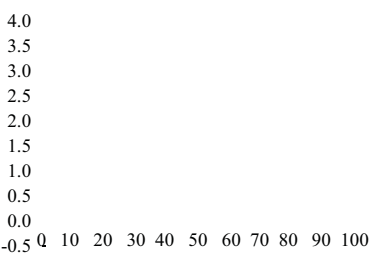

(c): $15 \mathrm{~kg}$

Fig. 2. Joint moments during squat and stoop lifting 


\subsection{Support moments}

Lower extremity joint moment could be analyzed with the concept of 'support moment' (Winter, 1980). Figure 3 shows that the contributions of each lower extremity joint for the support moment in two different lifting techniques. The dashed line in the figure represents the total support moment during lifting, and the height between two curves at any time represents the contribution to the support moment of that joint. At the initial stage of lifting, the hip and ankle joint extension moments were large during the squat lifting. On the other hand, during stoop lifting (the knee joint ROM was nearly zero), there were large knee flexion moments at the initial stage of lifting. Total support moments were larger in squat than in stoop because of the negative values of the knee moment in stoop lifting. Therefore, hip and ankle contributed to the most part of the support moment during squat lifting, and the knee flexion moment played an important role in the stoop lifting.

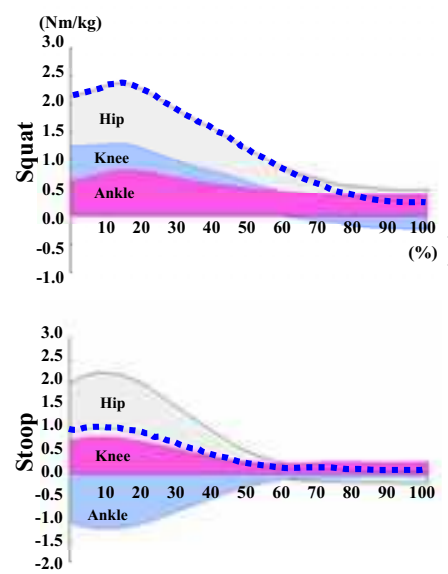

(a): $5 \mathrm{~kg}$
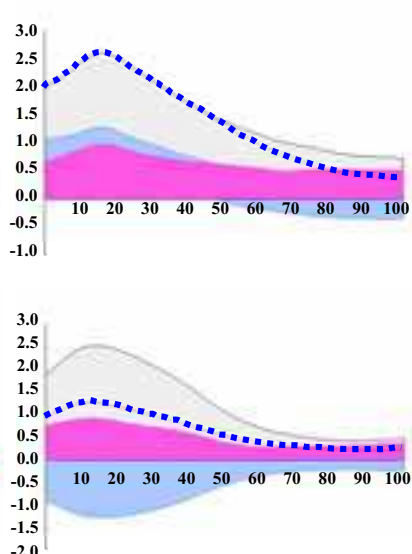

(b): $10 \mathrm{~kg}$
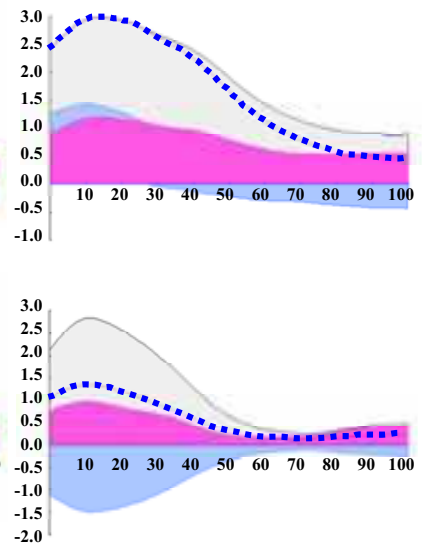

(c): $15 \mathrm{~kg}$

Fig. 3. Support moments during squat and stoop lifting

\subsection{Dynamic EMG}

Biceps femoris and rectus femoris showed large variances of activation during the squat lifting. Tibialis anterior, medial gastrocnemius, and biceps femoris showed large variances of activation during the stoop lifting (Fig. 4). Rectus abdominis and lumbar erector spinae had not significant differences between the squat and stoop lifting.

Co-contraction of the bi-articular knee antagonists (rectus femoris and biceps femoris) were observed markedly during the squat lifting. The concentric contraction of the tibialis anterior and the simultaneous eccentric contraction of the gastrocnemius during the stoop lifting also observed in the ankle joint. 

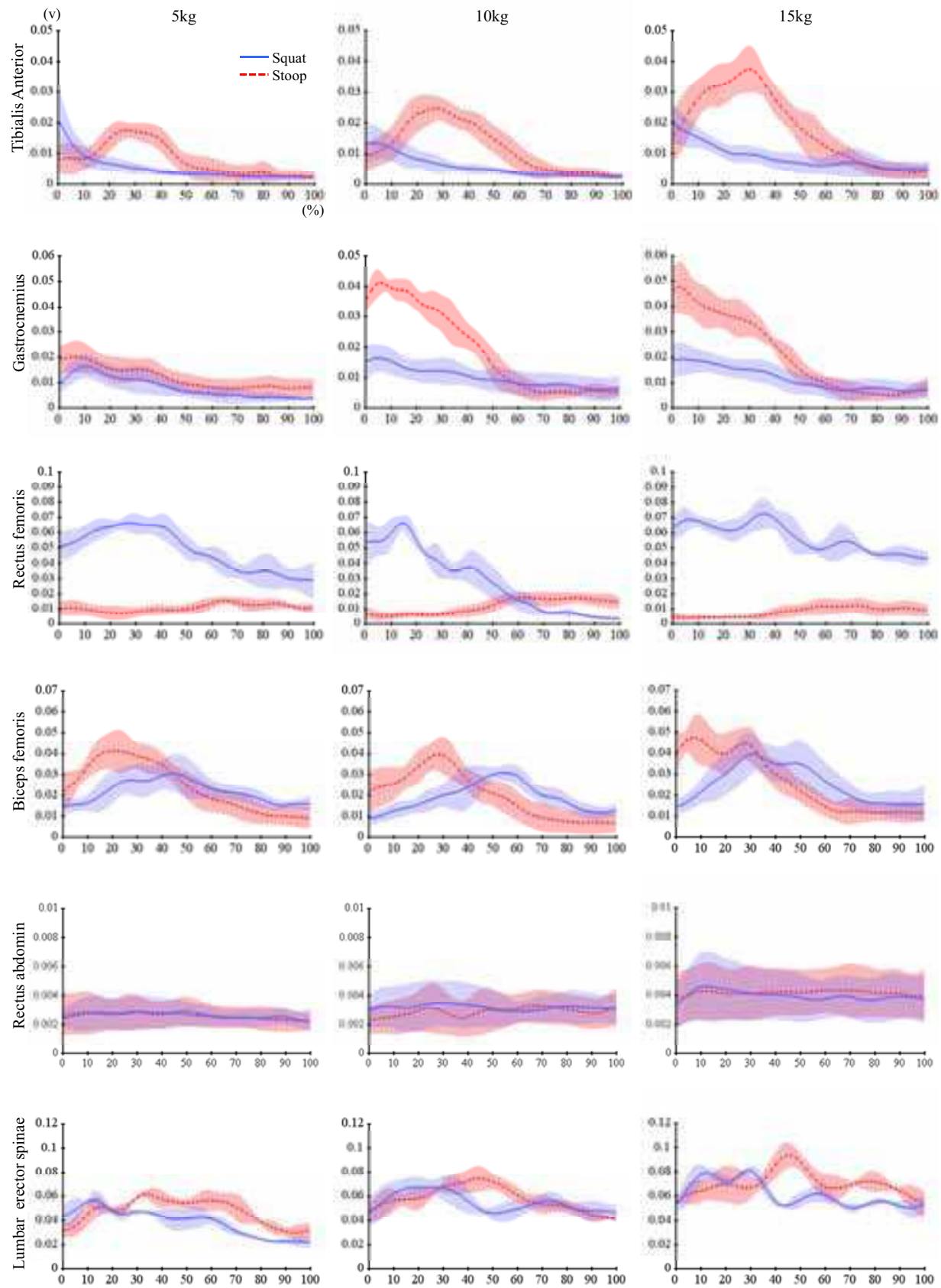

(a): $5 \mathrm{~kg}$

(b): $10 \mathrm{~kg}$

(c): $15 \mathrm{~kg}$

Fig. 4. Dynamic EMG during squat and stoop lifting 


\subsection{Lumbar curvature}

Fig. 5 represents the spine curvature when the lumbar lordosis appeared. Lumbar curvature was changed from the kyphosis to the lordosis about $50 \%$ in the squat lifting, and $60 \%$ in the stoop lifting regardless of weights. Lower limb joint angles and moments at that time were showed at Table 2, and its difference among the three different object weights were tested by the nonparametric central tendency test in the three groups $(5,10,15 \mathrm{~kg})$. The knee angle, the ankle angle, the lumbar moment had significant differences as the weight increased in the squat lifting. The lumbar angle, the lumbar moment and the hip moment had significant differences as the weight increased $(\mathrm{p}<0.05)$ in the stoop lifting. Table 3 shows the correlation coefficients between the "lumbar" and the "lower extremities", comparative parameters were the angles and moments. The knee angle in the squat, the hip and ankle angles in the stoop showed strong correlation with the lumbar angle. All three joint moments(hip, knee, ankle) showed the correlations with the lumbar moment in the squat lifting, however only the hip moment had the correlation with the lumbar moment in the stoop lifting $(\mathrm{p}<0.01)$.
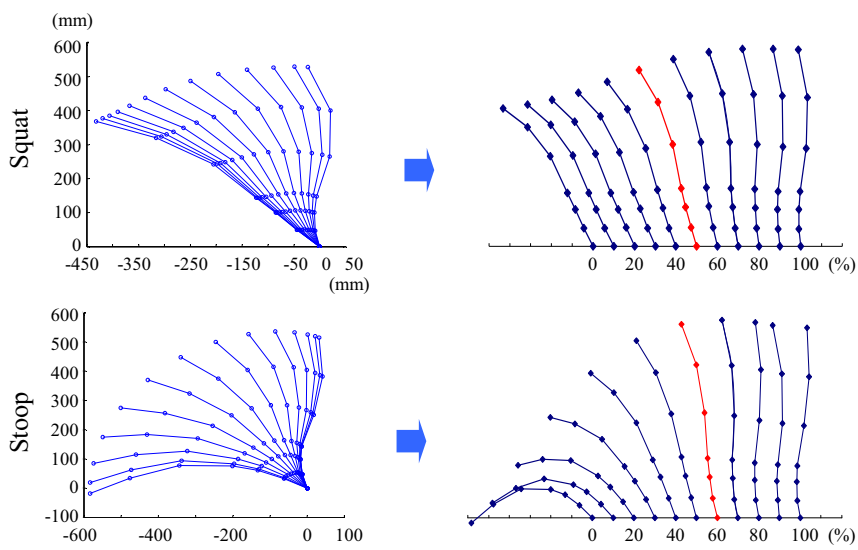

Fig. 5. Lumbar spine curvatures during squat and stoop lifting

\section{Discussion}

Without limitation of the assumption of biomechanical model used for calculation of kinematic and kinetic results, the limitations of this study were summarized as follows. We just analyzed the representative two lifting techniques on the assumption that they were symmetrical movements. In addition, the movements in the coronal/horizontal plane were not included in this study. Under the in-vitro examination, it was inevitable to keep the subject's motion under control - initial foot position, upper extremity position, knee flexion angle(semi-squat during squat lifting). The objects were not placed close enough to the body because the reflective markers could be hidden. In fact, lumbar could be often damaged mechanically due to the asymmetric or unbalanced lifting movement.

The heavy weight of object is also critical factor to the lumbar damage but $15 \mathrm{~kg}$ was assumed as heavy weight in this study for the safety of the subjects. 
The result of the maximum lumbar joint moment comparison between the squat and stoop lifting corresponded to the previous study that there was no conclusive evidence for advocating the squat lifting(van Dieen, 1999).

The support moment calculated by the summation of the extension moments in the previous study(Grag and Herrin, 1979) however all moments including flexion moments were summated for support moment in this study because the knee flexors could act as supporters.

It was expected that the joint moment results could be supported by the EMG results. However, the normalized EMG data had large variation among subjects and a lot of data excluded for analysis because of its failure of detection therefore we were focused on the activation patterns to interpret EMG data.

The lumbar lordosis appearance time was important during the lifting motion(Mitnitski et al., 1998; McGill et al., 2000; Gracovetsky, 1986; Dolan and Adams, 1993), thus we tried to find out the contributions of the lower extremities in relation to the lumbar joint.

The correlation coefficients between the lumbar and the lower extremity were investigated which were calculated by using the angles and moments at the time of lumbar lordosis appearance. The knee angle had the strong correlation with the lumbar angle in the squat lifting, and the hip and ankle angle had the correlation with the lumbar angle in the stoop lifting. These results showed representative kinematic characteristics of each lifting technique. All three lower extremity joint moments had the correlation with the lumbar joint in the squat lifting, and only the hip joint moment had the correlation with the lumbar joint in the stoop lifting.

There are three important bi-articular muscles in the lower body (rectus femoris, biceps femoris, gastrocnemius), and they affects two joints simultaneously(Doorenbosch et al., 1994; McGinity et al., 2000; Escamilla et al., 1998; Zajac et al., 2003).

In addition, the squat lifting as well as the stoop lifting is the typical closed kinetic chain motion(McGinity et al., 2000; Escamilla et al., 1998) so that the bi-articular muscle function is more complex(Lombard paradox(Lombard, 1903, 1907)). The EMG analysis and the calculation of individual muscle force change using simulation software could be helpful to determine these bi-articular muscle functions.

\section{Conclusions}

1) There were not significant differences in maximum lumbar joint moments between two techniques. Rather, the maximum lumbar extension moment was larger in squat than in stoop when $15 \mathrm{~kg}$ was lifted $(\mathrm{p}<0.05)$. This result advocates the previous study.

2) The hip and ankle joint contributed to the most part of the support moment during the squat lifting, and the knee flexion moment played an important role in the stoop lifting.

3) The ankle, hip and lumbar joints generated power and only the knee joint absorbed power in the squat lifting. The ankle and knee joints absorbed power and the hip and lumbar joints generated power in the stoop lifting.

4) The EMG results summarized that the co-contraction of the antagonists was observed markedly in the both lifting techniques; the tibialis anterior and the gastrocnemius in the ankle joint, the rectus femoris and the biceps femoris in the knee joint. 
5) At the time of lordotic curvature appearance in the squat lifting, strong correlations were found in all three lower extremity joint moments with the lumbar joint. On the other hand, in the stoop lifting, strong correlations existed in the hip moment with the lumbar joint.

In conclusion, considering the correlation with the lumbar joint, the kinetic factors generated by the ankle and hip joints (the extensor moment and the power generation) mostly lead the knee extension which is the remarkable kinematics in the squat lifting. The lumbar joint's kinematics (ROM) was the largest in stoop lifting. However, this movement couldn't be done safely without the knee joint's kinetic factors (the flexor moment, the antagonistic cocontraction of bi-articular muscles and the power absorption).

\section{References}

Campbell, C. \& Muncer S.J. (2005). Social Science and Medicine, Vol. 60, No. 2, 409 419, ISSN $0277-9536$

Stuart McGill. (2002). Low back disorders: Evidence-based prevention and rehabilitation. Human Kinetics, ISBN 0-7360-4241-5, Canada.

Koopman, F. S.; Edelaar, M.; Slikker, R.; Reynders, K.; van der Woude L. H. V. \& Marco H. J. M. (2004). American Journal of Physical Medicine \& Rehabilitation, Vol. 83, No. 2, 94103, ISSN 0894-9115.

Chen, Y. L. (2000). International Journal of Industrial Ergonomics, Vol. 25, 611-619, ISSN 01698141.

Burgess-Limerick, R.; Shemmell, J.; Barry, B. K.; Carson, R. G. \& Abernethy, B. (2001). Human Movement Science, Vol. 20, No.4-5, 549-562, ISSN 0167-9457.

Hsiang, S. M.; Brogmus, G. E.\& Courtney, T. K. (1997). International Journal of Industrial Ergonomics, Vol. 19, 59-74, ISSN 0169-8141.

van Dieen J. H.; Marco, H.J.M. \& Toussaint, H. M. (1999). Clinical Biomechanics, Vol. 14, 685696, ISSN 0268-0033.

Jager, M. \& Luttman, A. (1989). Ergonomics, Vol. 32, No. 1, 93-112, ISSN 0014-0139.

Straker L. (2003). International Journal of Industrial Ergonomics, Vol. 31, No. 3, 149-160, ISSN 0169-8141

Burgess-Limerick, R. (2003). International Journal of Industrial Ergonomics, Vol. 31, No.3, 143 148.

Garg, A. \& Moore, J. S. (1992). Occupational Medicine, Vol. 7, No. 4, 629-640, ISSN 0885-114X.

Garg, A. \& Herrin, G. D. (1979). American Institute of Industrial Engineers transactions, Vol. 11, 293-302, ISSN 0569-5554.

Welbergen, E.; Kemper, H. C. G.; Knibbe, J. J. \& Toussaint, H. M. Clijssen, L. (1991). Ergonomics, Vol. 34, 613-24, ISSN 0014-0139.

Duplessis, D. H.; Greenway, E. H.; Keene, K. L.; Lee, I. E.; Clayton, R. L. \& Metzler, T. (1998). Ergonomics, Vol. 41, No. 6, 790-797, ISSN 0014-0139.

Winter, D. A. (1980). Journal of Biomechanics, Vol. 13, 923-927, ISSN 0021-9290.

Hof, A. L. (2000). Gait \& Posture, Vol. 12, 196-199, ISSN 0966-6362.

Lombard, W. P. (1903). The Action of Two-joint Muscles, American Physics Education Revoluton, Vol. 8, 141-145, ISSN.

Lombard, W. P. \&. Abbott, F. M. (1907). American Journal of Physics, Vol. 20, 1-60, ISSN 00029505. 
Doorenbosch, C. A. M.; Harlaar, J.; Roebroeck, M. E. \& Lankhorst, G. J. (1994). Journal of Biomechanics, Vol. 27, 1299-1307, ISSN 0966-6362.

McGinity, G.; Irrgang, J. J. \& Pezzullo, D. (2000). Clinical Biomechanics, Vol. 15, 160-166, ISSN 0268-0033.

Escamilla, R. F.; Fleisig, G. S.; Zheng, N.; Barrentine, S. W.; Wilk, K. E. \& Andrews, J. R. (1998). Medine\& Science in Sports \& Exercise, Vol. 30, 556-569, ISSN 0195-9131.

Zajac, F. E.; Neptune, R. R.; Kautz, S. A. (2003). Gait \& Posture, Vol. 17, 1-17, ISSN 0966-6362.

Mitnitski, A. B.; Yahia, L. H.; Newman, N. M.; Gracovetsky, S. A. \& Feldman, A. G. (1998). Clinical Biomechanics, Vol. 13, 121-127, ISSN 0268-0033.

McGill, S. M.; Hughson, R. L. \& Parks K. (2000). Clinical Biomechanics, Vol. 15, 777-780, ISSN 0268-0033.

Gracovetsky, G. (1986). Journal of Biomedical Engineering, Vol. 8, 217-223, ISSN 0141-5425.

Dolan, P. \& Adams, M. A. (1993). Clinical Biomechanics, Vol. 8, 185-192, ISSN 0268-0033.

Welbergen, E.; Kemper, H. C. G.; Knibbe, J. J.; Toussaint, H. M. \& Clijssen, L. (1991). Ergonomics, Vol. 34, 613-624, ISSN 0014-0139.

Duplessis, D. H.; Greenway, E. H.; Keene, K. L.; Lee, I. E.; Clayton, R. L. \& Metzler, T. (1998). Ergonomics, Vol. 41, 790-797, ISSN 0014-0139.

David, A. Winter (2004). Biomechanics and Motor Control of Human Movement, John Wiley \& Sons, Inc., 3rd edition, ISBN 978-0-471-44989-8. 


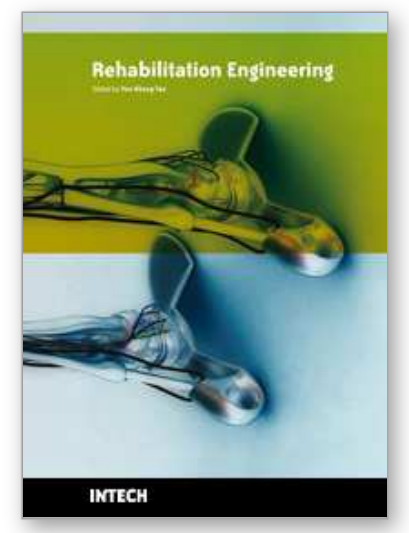

\author{
Rehabilitation Engineering \\ Edited by Tan Yen Kheng
}

ISBN 978-953-307-023-0

Hard cover, 288 pages

Publisher InTech

Published online 01, December, 2009

Published in print edition December, 2009

Population ageing has major consequences and implications in all areas of our daily life as well as other important aspects, such as economic growth, savings, investment and consumption, labour markets, pensions, property and care from one generation to another. Additionally, health and related care, family composition and life-style, housing and migration are also affected. Given the rapid increase in the aging of the population and the further increase that is expected in the coming years, an important problem that has to be faced is the corresponding increase in chronic illness, disabilities, and loss of functional independence endemic to the elderly (WHO 2008). For this reason, novel methods of rehabilitation and care management are urgently needed. This book covers many rehabilitation support systems and robots developed for upper limbs, lower limbs as well as visually impaired condition. Other than upper limbs, the lower limb research works are also discussed like motorized foot rest for electric powered wheelchair and standing assistance device.

\title{
How to reference
}

In order to correctly reference this scholarly work, feel free to copy and paste the following:

Seonhong Hwang, Youngeun Kim and Youngho Kim (2009). Lower Extremity Joint Moments during Squat and Stoop Lifting, Rehabilitation Engineering, Tan Yen Kheng (Ed.), ISBN: 978-953-307-023-0, InTech, Available from: http://www.intechopen.com/books/rehabilitation-engineering/lower-extremity-joint-moments-duringsquat-and-stoop-lifting

\section{INTECH}

open science | open minds

\section{InTech Europe}

University Campus STeP Ri

Slavka Krautzeka 83/A

51000 Rijeka, Croatia

Phone: +385 (51) 770447

Fax: +385 (51) 686166

www.intechopen.com

\section{InTech China}

Unit 405, Office Block, Hotel Equatorial Shanghai

No.65, Yan An Road (West), Shanghai, 200040, China

中国上海市延安西路65号上海国际贵都大饭店办公楼 405 单元

Phone: +86-21-62489820

Fax: +86-21-62489821 
(C) 2009 The Author(s). Licensee IntechOpen. This chapter is distributed under the terms of the Creative Commons Attribution-NonCommercial-ShareAlike-3.0 License, which permits use, distribution and reproduction for non-commercial purposes, provided the original is properly cited and derivative works building on this content are distributed under the same license. 